\title{
Propyl gallate reduces the growth of lung cancer cells through caspase-dependent apoptosis and G1 phase arrest of the cell cycle
}

\author{
WOO HYUN PARK \\ Department of Physiology, Medical School, Research Institute for Endocrine Sciences, \\ Jeonbuk National University, Jeonju, Jeollabuk 54907, Republic of Korea
}

Received April 22, 2020; Accepted September 29, 2020

DOI: $10.3892 /$ or.2020.7815

\begin{abstract}
Propyl gallate (3,4,5-trihydroxybenzoic acid propyl ester; PG) is a synthetic phenolic antioxidant which exerts many effects on tissue and cell functions. In the present study, Calu-6 and A549 lung cancer cells were used to examine the molecular mechanism of the anti-growth effects of PG in relation to apoptosis and cell cycle arrest. PG inhibited the growth of both lung cancer cell types in a dose-dependent manner with an $\mathrm{IC}_{50}$ of $800 \mu \mathrm{M}$ at $24 \mathrm{~h}$ based on MTT assays. DNA flow cytometry showed that PG induced G1 phase arrest of the cell cycle in Calu- 6 and A549 cells. In addition, PG induced apoptosis in both lung cancer cell types, as evidenced by sub-G1 cell population and Annexin V-stained cells. Western blot results demonstrated that PG decreased the Bcl-2 level which was accompanied by an increase in the cleaved form of poly(ADP-ribose) polymerase (PARP). PG also triggered loss of mitochondrial membrane potential (MMP; $\Delta \Psi \mathrm{m}$ ) and decreased MMP $(\Delta \Psi \mathrm{m})$ levels in both lung cancer cell types, as assessed by FACS analysis. Furthermore, PG upregulated the activities of caspase- 3 and caspase- 8 in Calu- 6 cells. In conclusion, PG treatment inhibited the growth of lung cancer cells, especially Calu-6 cells via caspase-dependent apoptosis as well as G1 phase arrest of the cell cycle.
\end{abstract}

Correspondence to: Professor Woo Hyun Park, Department of Physiology, Medical School, Research Institute for Endocrine Sciences, Jeonbuk National University, 20 Geonji-ro, Deokjin, Jeonju, Jeollabuk 54907, Republic of Korea

E-mail: parkwh71@jbnu.ac.kr

Abbreviations: PG, propyl gallate; NSCLC, non-small cell lung cancer; SCLC, small cell lung cancer; PARP, poly(ADP-ribose) polymerase; MMP $\left(\Delta \Psi_{\mathrm{m}}\right)$, mitochondrial membrane potential; MTT, 3-(4,5-dimethylthiazol-2-yl)-2,5-diphenyltetrazolium bromide; FITC, fluorescein isothiocyanate

Key words: lung cancer, propyl gallate, cell growth, apoptosis, caspase, cell cycle

\section{Introduction}

Propyl gallate (PG; 3,4,5-trihydroxybenzoic acid propyl ester), a synthetic antioxidant, has been utilized for decades as an additive for processed food, cosmetics, food packing, and the pharmaceutical industry since it can be used to avoid spoilage and decomposition (1). Although PG is reported to have low toxicity, it has various beneficial properties for tissue and cell functions. For example, PG is an efficient protector of liver cells from lipid peroxidation by oxygen radicals (2). In addition, numerus studies have revealed that PG functions as an antioxidant and a chemopreventive agent in vivo and in vitro (3-5). In contrast, $\mathrm{PG}$ also exerts some prooxidant effects $(6,7)$. In addition, $\mathrm{PG}$ mediates its cytotoxicity through the impediment of mitochondrial function in hepatocytes, endothelial cells and testicular cells (8-10). PG decreases the growth of microorganisms by constraining respiration and nucleic acid synthesis (11). Therefore, in order to clarify the discrepancies between the different effects of PG as an antioxidant or a prooxidant, further studies are required to re-evaluate its function and effects on cells and tissues.

The cell cycle is the series of events that takes place in a cell. The eukaryotic cell cycle consists of four distinct phases: The G1 phase, S phase, G2 phase and M phase $(12,13)$. Proper progression throughout the cell cycle depends on the expression level of a family of cyclins, and the subsequent activation of cyclin-dependent kinases (CDKs) (12). Regulation of the cell cycle involves procedures crucial to cell survival, including the recognition and repair of genetic damage as well as the prevention of uncontrolled cell division $(12,13)$. Apoptosis is a cellular response to cytotoxicological drugs $(14,15)$. The signaling mechanism of apoptosis commonly consists of two pathways: The mitochondrial pathway and cell death receptor pathway (14-16). The commencement of apoptosis in the mitochondrial pathway is induced or accompanied by increasing BAX protein levels and decreasing Bcl-2 protein levels, causing the loss of mitochondrial membrane potential (MMP; $\Delta \Psi \mathrm{m})$ (14). The focal point of this pathway is the efflux of cytochrome $c$ from mitochondria to the cytosol. In the cytosol, cytochrome $c$ forms an apoptosome complex with apoptotic protease-activating factor 1 and caspase-9, inducing the activation of a major executioner caspase, caspase-3 $(15,17)$. The cell death receptor pathway is distinguished by the 
connection of cell death ligands to their death receptors with subsequent stimulation of caspase- 8 and caspase- 3 activities (16). Caspase- 3 activation can systematically disassemble cells by severing key proteins, particularly poly(ADP-ribose) polymerase (PARP). Therefore, targeted inhibition of cell cycle progression and anti-apoptotic pathways is an attractive concept for improving cancer treatment strategies.

Lung cancer is the chief cause of cancer-related death worldwide (18). Lung cancer is classified into two main types: Small cell lung cancer (SCLC) which accounts for 10-14\% of all lung cancer cases, and non-SCLC (NSCLC) which accounts for $85-90 \%(18,19)$. NSCLC is additionally sorted into three subtypes in accordance with histology: Adenocarcinoma, squamous-cell carcinoma, and large cell carcinoma (19). The anti-growth effects of PG have been confirmed in numerous cell types such as pulmonary artery and umbilical vein endothelial cells $(10,20)$, testis cells (9), leukemia cells (21), and hepatocellular carcinoma (22). We also reported that PG inhibits the growth of HeLa cells via apoptosis and glutathione depletion $(23,24)$. Although numerous studies have suggested that PG plays a crucial role in cell death, very little is known about the cytotoxic and anti-growth effects of PG in lung cancer cells. In the present study, human SCLC Calu-6 and NSCLC adenocarcinoma A549 cells were used to investigate the molecular mechanism involved in the anti-growth effect of PG concerning apoptosis as well as cell cycle arrest. PG inhibited the growth of these lung cancer cells via apoptosis and G1 phase arrest of the cell cycle.

\section{Materials and methods}

Cell culture. Human SCLC Calu-6 cells and NSCLC adenocarcinoma A549 cells were obtained from the American Type Culture Collection (ATCC). These cell lines were maintained in a standard humidified incubator containing $5 \% \mathrm{CO}_{2}$ at $37^{\circ} \mathrm{C}$. The lung cancer cells were cultured in RPMI-1640 medium containing 10\% fetal bovine serum (FBS) (Sigma-Aldrich; Merck KGaA) and $1 \%$ penicillin-streptomycin (Gibco BRL; Thermo Fisher Scientific, Inc.). Cells were grown in BD Falcon 100-mm plastic cell culture dishes (BD Biosciences) and harvested with trypsin-EDTA (Gibco BRL; Thermo Fisher Scientific, Inc.). Exponentially growing cells were used for the experiments.

Reagents. PG was acquired from Sigma-Aldrich Co (Merck KGaA). PG was dissolved in ethanol at $200 \mathrm{mM}$ as a stock solution. Ethanol $(0.2 \%)$ was used as a control vehicle and did not influence cell growth or cell death. Stock solution was wrapped in foil and kept at $4{ }^{\circ} \mathrm{C}$ or $-20^{\circ} \mathrm{C}$.

Cell growth inhibition assay. The influence of PG on the growth of lung cancer cells was determined using 3-(4,5-dimethylthiazol-2-yl)-2,5-diphenyltetrazolium bromide (MTT, Sigma-Aldrich; Merck KGaA) assays. Briefly, $5 \times 10^{4}$ cells were seeded into each well of 96 -well microtiter plates (Nunc). After incubation with the designated doses of PG for 24 or $72 \mathrm{~h}, 20 \mu \mathrm{l}$ of MTT solution $[2 \mathrm{mg} / \mathrm{ml}$ in phosphate-buffered saline (PBS); Gibco BRL; Thermo Fisher Scientific, Inc.] was added to each well. The plates were incubated for $4 \mathrm{~h}$ at $37^{\circ} \mathrm{C}$. The medium in plates was removed via pipetting, and 100-200 $\mu \mathrm{l}$ of DMSO was added to each well to solubilize formazan crystals. Optical density was measured at $570 \mathrm{~nm}$ with a microplate reader (Synergy ${ }^{\mathrm{TM}}$ 2, BioTekR Instruments Inc.). Each plate contained multiple wells at a given experimental condition and multiple control wells. This procedure was replicated for 2 to 4 plates per condition.

Cell cycle and sub-G1 cell analysis. Cell cycle and sub-G1 distributions in cells were determined using propidium iodide (PI, Sigma-Aldrich; Merck KGaA; Ex/Em = $488 \mathrm{~nm} / 617 \mathrm{~nm}$ ) staining. Briefly, $1 \times 10^{6}$ cells in BD Falcon $60-\mathrm{mm}$ culture dishes (BD Biosciences) were incubated with the designated concentrations of PG for 24 or $72 \mathrm{~h}$. Cells were washed twice with PBS and fixed in cold $70 \%$ ethanol. Cells were again washed with PBS, and then incubated with $10 \mu \mathrm{g} / \mathrm{ml}$ PI concurrently with RNase (Sigma-Aldrich; Merck KGaA) at a concentration of $5 \times 10^{5}$ cells $/ \mathrm{ml}$ in $\mathrm{PBL}$ at $37^{\circ} \mathrm{C}$ for $30 \mathrm{~min}$. The proportions of cells in different phases of the cell cycle or having sub-G1 DNA content were measured and analyzed with a FACStar flow cytometer (BD Sciences).

Detection of apoptosis. Apoptosis was identified via Annexin V-fluorescein isothiocyanate staining (FITC, Thermo Fisher Scientific, Inc.; Ex/Em = 488/519 nm). Annexin V-FITC is used to detect phosphatidylserine exposing cells thereby marking apoptotic cells. Briefly, $1 \times 10^{6}$ cells in BD Falcon 60-mm culture dishes (BD Biosciences) were incubated with the designated concentrations of PG for 24 or $72 \mathrm{~h}$. Cells were washed twice with cold PBS and then suspended in $200 \mu \mathrm{l}$ of binding buffer (10 mM HEPES/NaOH $\mathrm{pH} 7.4,140 \mathrm{mM} \mathrm{NaCl}, 2.5 \mathrm{mM} \mathrm{CaCl}_{2}$ ) at a concentration of $5 \times 10^{5}$ cells $/ \mathrm{ml}$ at $37^{\circ} \mathrm{C}$ for $30 \mathrm{~min}$. Annexin V-FITC $(2 \mu \mathrm{l})$ was added to the solution, and cells were analyzed with a FACStar flow cytometer (BD Sciences).

Measurement of mitochondrial membrane potential $(M M P ; \Delta \Psi \mathrm{m})$. The MMP $(\Delta \Psi \mathrm{m})$ was monitored using a Rhodamine 123 cationic fluorescent dye (Sigma-Aldrich; Merck KGaA;Ex $/ E m=485 / 535 \mathrm{~nm}$ ), which preferentially enters into mitochondria with high MMP $(\Delta \Psi \mathrm{m})$. Depolarization of MMP $(\Delta \Psi \mathrm{m})$ results in the loss of Rhodamine 123 from the mitochondria and reduces the intracellular fluorescence intensity of this dye. In brief, $1 \times 10^{6}$ cells in $60-\mathrm{mm}$ culture dishes (Nunc) were incubated with the indicated doses of PG for $24 \mathrm{~h}$. Cells were washed twice with PBS and incubated with Rhodamine $123(0.1 \mathrm{mg} / \mathrm{ml})$ at a concentration of $5 \times 10^{5}$ cells/ $\mathrm{ml}$ in $\mathrm{PBL}$ at $37^{\circ} \mathrm{C}$ for $30 \mathrm{~min}$. Rhodamine 123 staining intensities were determined using a FACStar flow cytometer (BD Sciences). Rhodamine 123 negative (-) cells indicated the loss of MMP $(\Delta \Psi \mathrm{m})$ in the lung cancer cells. MMP $\left(\Delta \Psi_{\mathrm{m}}\right)$ levels in cells, except MMP $\left(\Delta \Psi_{\mathrm{m}}\right)$ loss cells, were expressed as proportions compared with the control cells.

Western blot analysis. Protein expression levels were evaluated via western blotting. Briefly, $5 \times 10^{6}$ cells in BD Falcon 100 -mm culture dishes (BD Biosciences) were incubated with the indicated concentrations of $\mathrm{PG}$ for $24 \mathrm{~h}$. Cells were washed with PBS and 4 volumes of lysis buffer (Intron Biotechnology) was added. Total proteins $(30 \mu \mathrm{g})$ were resolved via 8-15\% SDS-PAGE gels and then transferred to Immobilon-P 

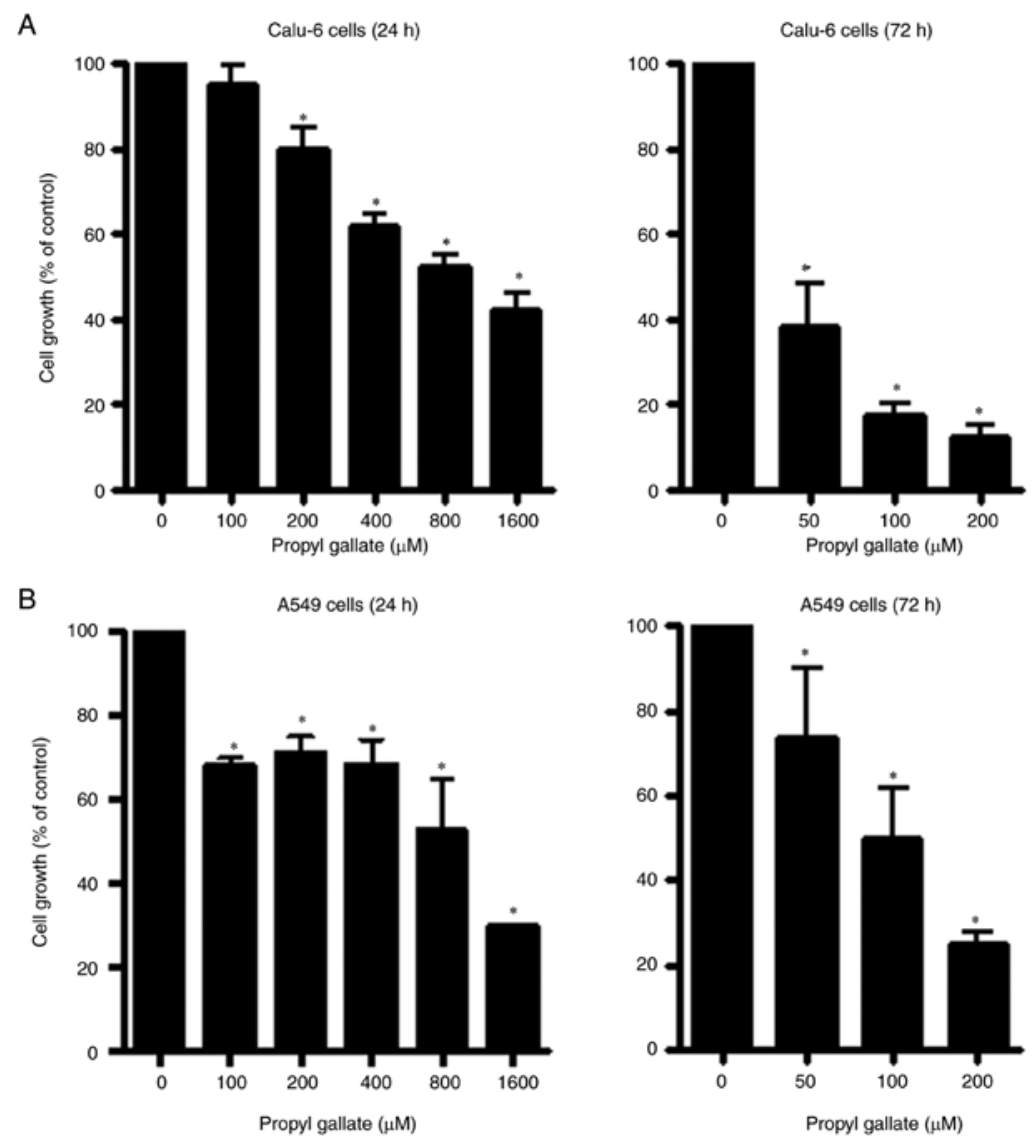

Figure 1. Effects of PG on cell growth in Calu-6 and A549 lung cancer cells. Exponentially growing cells were incubated in the presence of the designated concentrations of PG for 24 or $72 \mathrm{~h}$. Cell growth was evaluated by MTT assays. Graphs show cell growth in (A) Calu- 6 and (B) A549 cells. "P<0.05 compared with the PG-untreated control cells. PG, propyl gallate.

PVDF membranes (Millipore) by electroblotting. Membranes were probed with anti-Bcl-2 (cat. no. 2872, 1:1,000 dilution), anti-caspase-3 (cat. no. 9662, 1:1,000 dilution), anti-PARP (cat. no. 9542, 1:1,000 dilution), anti-cleaved PARP (cat. no. 9541, 1:1,000 dilution) antibodies (Cell Signaling Technology, Inc.), and anti- $\beta$-actin antibody (sc-81178, 1:1,000 dilution, Santa Cruz Biotechnology, Inc.). Membranes were incubated with horseradish peroxidase-conjugated secondary antibodies (sc-2004 or sc-2005, 1:1,000 dilution, Santa Cruz Biotechnology, Inc.). Western blots were developed using an EZ-Western Lumi Pico ECL solution kit (DoGen, Korea).

Quantification of caspase- 3 and caspase- 8 activities. The activities of caspase- 3 and caspase- 8 were evaluated using Caspase-3 and Caspase- 8 Colorimetric Assay Kits (R\&D Systems, Inc.). In brief, $1 \times 10^{6}$ cells were incubated with the specified concentrations of PG for $24 \mathrm{~h}$. Cells were washed with PBS and 4 volumes of lysis buffer (Intron Biotechnology) was added. Samples containing $50 \mu \mathrm{g}$ of total protein were added to $2 \mathrm{X}$ Reaction buffer containing DEVD-pNA for caspase-3 activity or IETD-pNA for caspase- 8 activity in 96-well microtiter plates (Nunc) and incubated at $37^{\circ} \mathrm{C}$ for $1 \mathrm{~h}$. Optical density was measured at $405 \mathrm{~nm}$ using a microplate reader (Synergy ${ }^{\mathrm{TM}}$ 2). Each plate contained multiple wells of a given experimental condition as well as multiple control wells. Caspase activity is expressed in arbitrary absorbance units (absorbance at a wavelength of $405 \mathrm{~nm}$ ).
Statistical analysis. The results represent the mean of at least three independent experiments (mean $\pm \mathrm{SD}$ ). Data were analyzed using Instat software (GraphPad Prism 5.0; GraphPad Software, Inc.). One-way analysis of variance with post hoc analysis using Tukey's multiple comparison test was applied to judge statistical significance which was defined at $\mathrm{P}<0.05$.

\section{Results}

Effects of PG on the growth of Calu-6 and A549 lung cancer cells. The effect of PG on the growth of Calu-6 and A549 lung cancer cell types was observed using MTT assays. A dose-dependent reduction in cell growth was observed in Calu-6 cells with a half maximal inhibitory concentration $\left(\mathrm{IC}_{50}\right)$ of approximately $800 \mu \mathrm{M}$ following treatment with PG for $24 \mathrm{~h}$ (Fig. 1A). Additionally, a $50 \mu \mathrm{M}$ concentration of PG appeared to significantly reduce the growth of Calu- 6 cells by approximately $60 \%$ at $72 \mathrm{~h}$ (Fig. $1 \mathrm{~A}$ ). Thus, the $\mathrm{IC}_{50}$ of $\mathrm{PG}$ in Calu- 6 cells at $72 \mathrm{~h}$ was less than $50 \mu \mathrm{M}$. The growth of A549 cells was also reduced with an $\mathrm{IC}_{50}$ of $\sim 800 \mu \mathrm{M}$ after a 24-h incubation with PG (Fig. 1B). In addition, the $\mathrm{IC}_{50}$ of PG in A549 cells at $48 \mathrm{~h}$ was approximately $150 \mu \mathrm{M}$ (data not shown). Treatment with $100 \mu \mathrm{M}$ PG decreased the growth of A549 cells by approximately $50 \%$ at 72 h (Fig. 1B).

Effects of PG on the cell cycle distribution of lung cancer cells. Because the growth inhibition of Calu- 6 and A549 cells by 
A
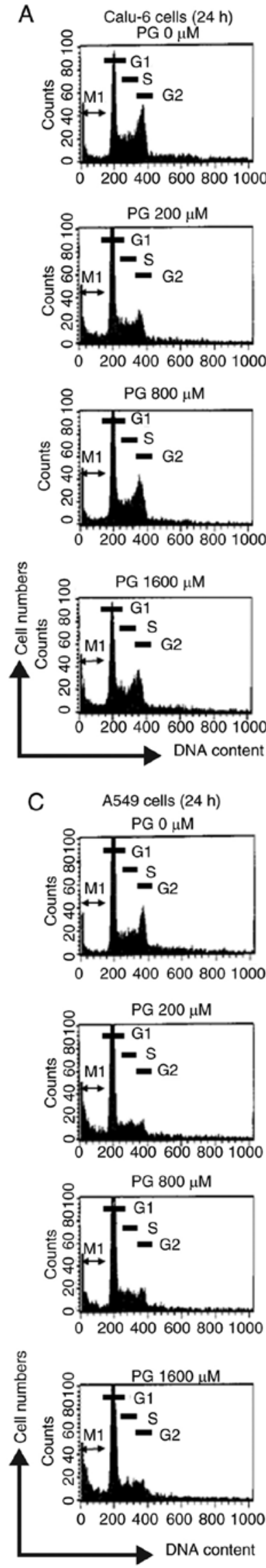
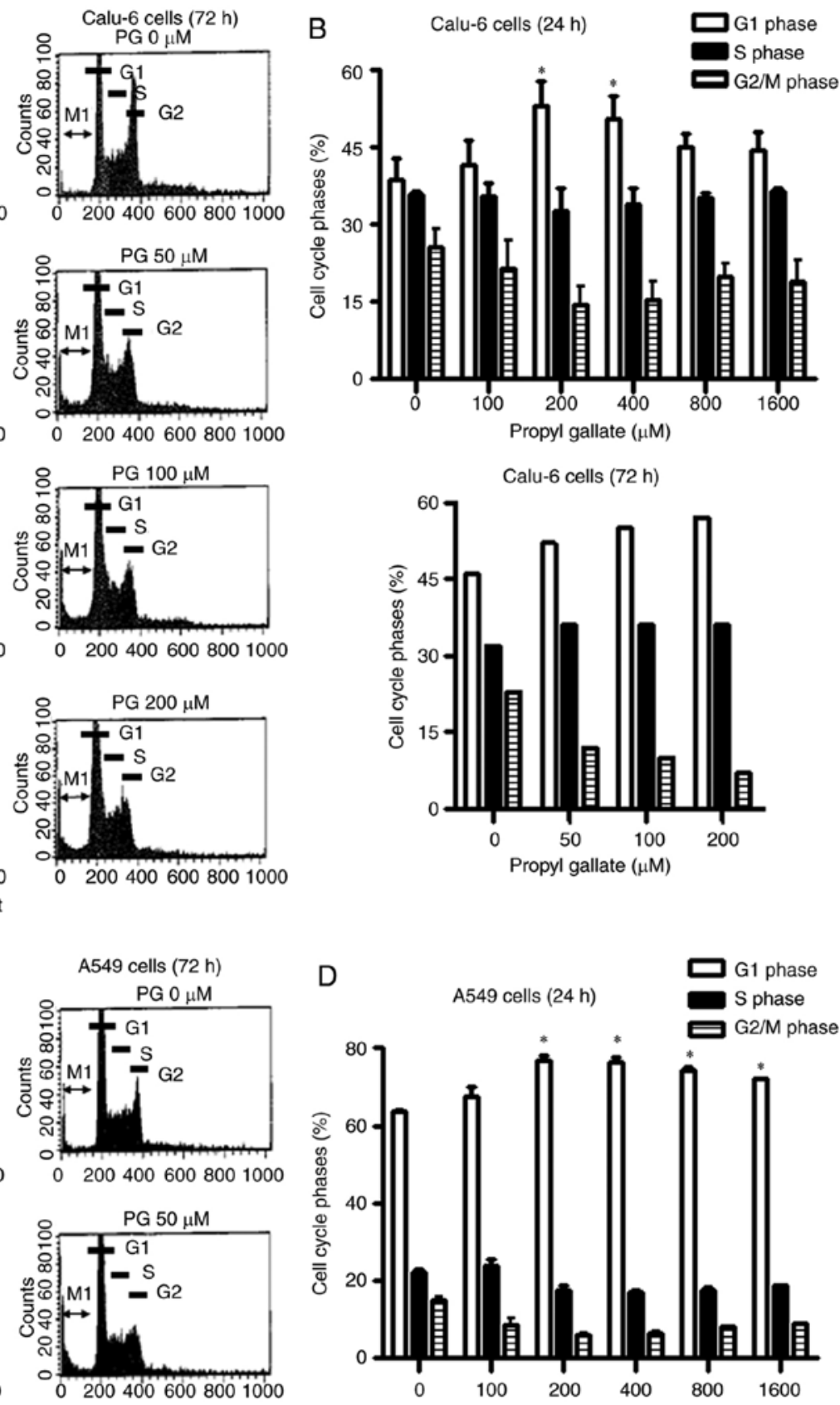

$\mathrm{PG} 100 \mu \mathrm{M}$
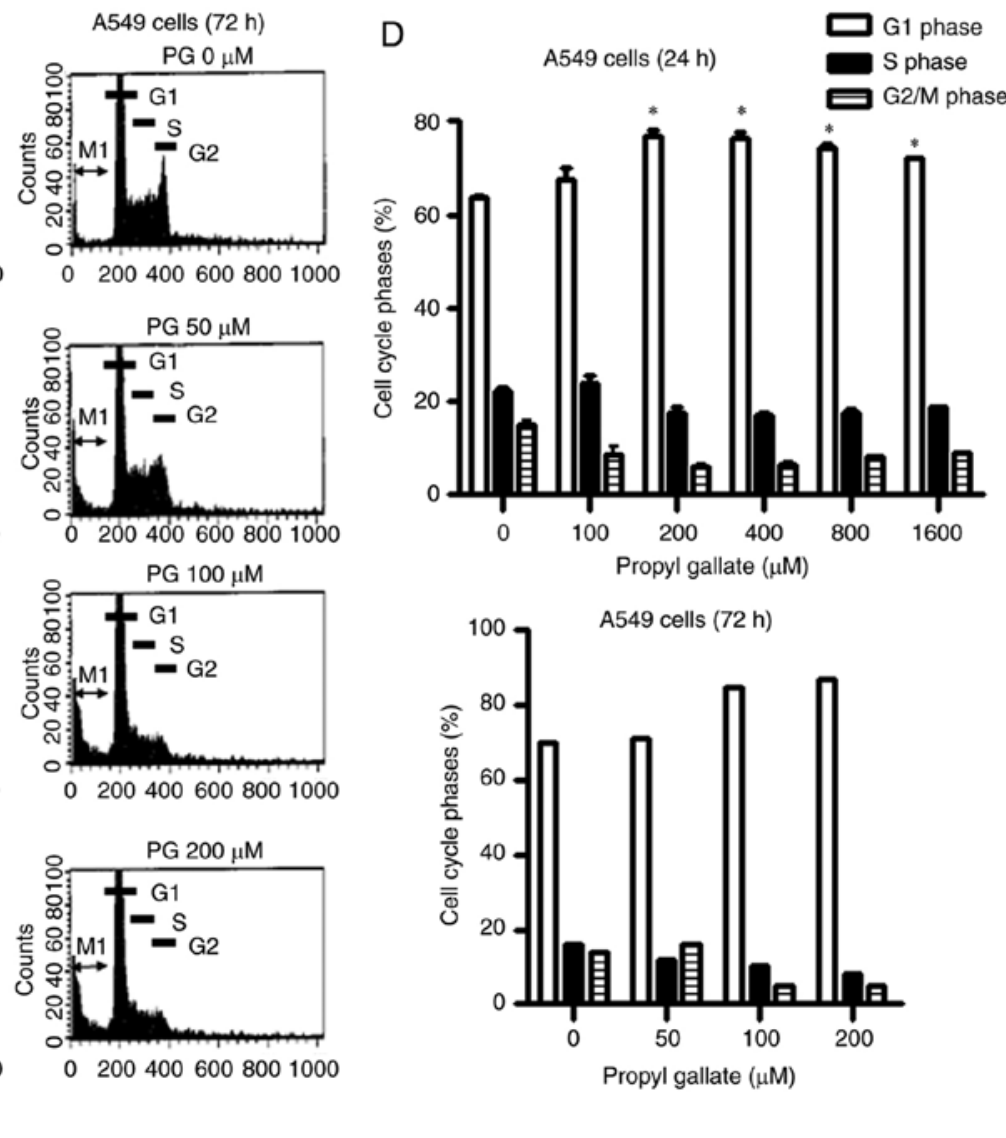

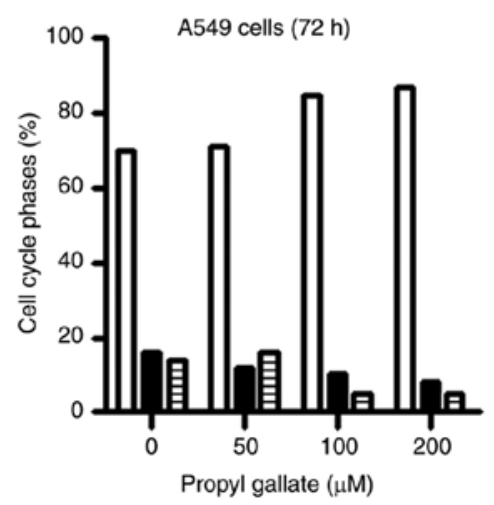

Figure 2. Effects of PG on cell cycle phase distribution in lung cancer cells. Exponentially growing cells were incubated in the presence of the designated concentrations of PG for $24(0-1,600 \mu \mathrm{M})$ or $72 \mathrm{~h}(0-200 \mu \mathrm{M})$. Cell cycle phase distribution was evaluated by DNA flow cytometry. (A and C) Each histogram shows the cell cycle distributions in PG-treated (A) Calu-6 and (C) A549 lung cancer cells at 24 and 72 h. M1 indicates sub-G1 cells. G1, S, and G2 represent each phase of the cell cycle. (B and D) Graphs show cell cycle phase distribution derived from G1, S, and G2 phases in A and C in (B) Calu-6 and (D) A549 cells, respectively. ${ }^{*} \mathrm{P}<0.05$ compared with the $\mathrm{PG}-$ untreated control cells. PG, propyl gallate. 
A

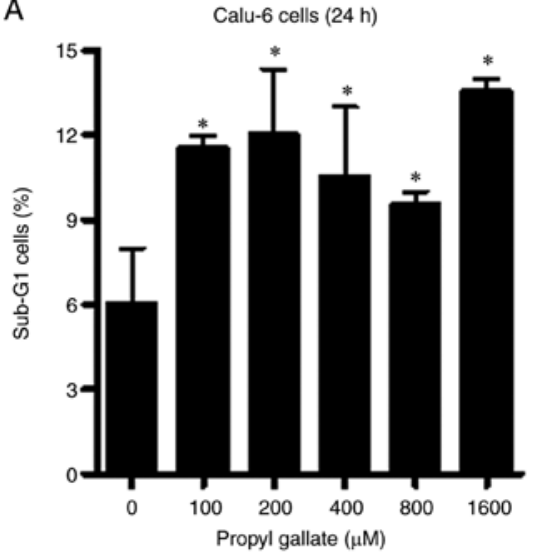

B

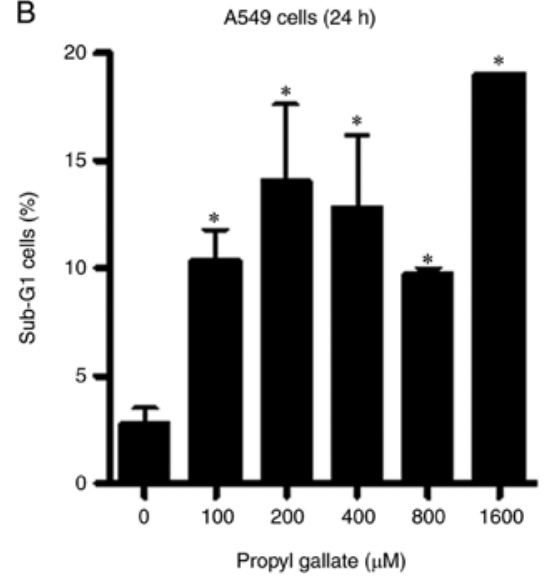

Calu- 6 cells $(72 \mathrm{~h})$
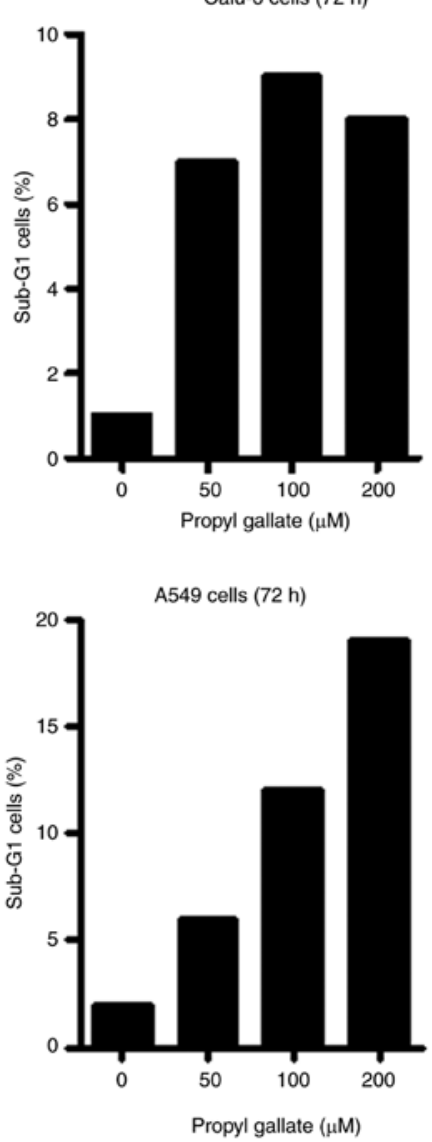

Figure 3. Effects of PG on sub-G1 cells in lung cancer cells. Exponentially growing cells were incubated in the presence of the designated concentrations of PG for 24 or $72 \mathrm{~h}$. Sub-G1 cells were measured with FACStar flow cytometer. (A and B) Graphs show the proportions of sub-G1 cells derived from M1 in Fig. 2A and C in (A) Calu-6 and (B) A549 cells, respectively. ${ }^{*} \mathrm{P}<0.05$ compared with the PG-untreated control cells. PG, propyl gallate.

PG could be explained by an arrest during cell cycle progression, allocations of cells in different stages of the cell cycle were observed after a 24 - or 72-h incubation period with PG. DNA flow cytometric analysis indicated that tested doses of PG induced a G1 phase arrest of the cell cycle in Calu- 6 cells at 24 and $72 \mathrm{~h}$ (Fig. 2A and B). Particularly, concentrations of 200 and $400 \mu \mathrm{M}$ PG showed a significant increase in the G1 phase at $24 \mathrm{~h}$ (Fig. 2A and B). In addition, the tested doses of PG induced a G1 phase arrest of the cell cycle in A549 cells at $24 \mathrm{~h}$ (Fig. 2C and D). Treatment with 100 and $200 \mu \mathrm{M} \mathrm{PG}$ also increased the proportion of cells at the G1 phase at $72 \mathrm{~h}$ (Fig. 2C and D).

Effects of PG on cell death in lung cancer cells. Whether PG induces cell death was evaluated using sub-G1 cells and Annexin V-staining cells. As shown in Fig. 3A, the tested doses of PG increased the quantity of sub-G1 cells in Calu- 6 cells at 24 or $72 \mathrm{~h}$, but the effects were not dose-dependent. PG also increased the quantity of sub-G1 cells in A549 cells at 24 or $72 \mathrm{~h}$ (Fig. 3B). Furthermore, $100-400 \mu \mathrm{M}$ PG did not increase the percentage of Annexin V-stained cells in both Calu-6 (Fig. 4A and B) and A549 cell lines (Fig. 4A and C) and $800 \mu \mathrm{M}$ PG slightly increased the percentage of Annexin V-staining cells in these cells (Fig. 4). However, the percentage of Annexin V-stained cells in Calu-6 and A549 cells was significantly increased after treatment with 1,600 $\mu \mathrm{M}$ PG at $24 \mathrm{~h}$ (Fig. 4).
Effects of PG on mitochondrial membrane potential (MMP; $\Delta \Psi m$ ) in lung cancer cells. As apoptosis is closely related to the collapse of MMP $(\Delta \Psi \mathrm{m})$, loss of MMP $(\Delta \Psi \mathrm{m})$ in PG-treated cells was evaluated using Rhodamine 123 dye. Loss of MMP $(\Delta \Psi \mathrm{m})$ in both lung cancer cell types was dose-dependently induced by PG at concentrations of $100-1,600 \mu \mathrm{M}$ at $24 \mathrm{~h}$ (Fig. 5A-C). After exposure to $800 \mu \mathrm{M}$ PG, the proportions of cells with MMP $\left(\Delta \Psi_{\mathrm{m}}\right)$ loss in Calu-6 and A549 cell lines were approximately 30 and $45 \%$, respectively (Fig. 5A-C). In relation to the levels of MMP $\left(\Delta \Psi_{\mathrm{m}}\right)$ in both lung cancer cell lines at $24 \mathrm{~h}, 100 \mu \mathrm{M}$ PG increased the MMP $\left(\Delta \Psi_{\mathrm{m}}\right)$ level in Calu-6 cells whereas PG at 200-1,600 $\mu \mathrm{M}$ significantly decreased the MMP $\left(\Delta \Psi_{\mathrm{m}}\right)$ level in these cells (Fig. 5A and D). Treatment with 100-1,600 $\mu \mathrm{M}$ PG also reduced MMP $\left(\Delta \Psi_{\mathrm{m}}\right)$ levels in A549 cells (Fig. 5A and E). The levels of MMP $\left(\Delta \Psi_{\mathrm{m}}\right)$ were approximately 30 and $20 \%$ in Calu- 6 and A549 cell lines treated with $800 \mu \mathrm{M}$ PG, respectively (Figs. 5A, D and E).

Effects of PG on apoptosis-related protein levels and activities of caspases in lung cancer cells. Since PG induced cell death in both lung cancer cell types, the levels of apoptosis-related proteins were assessed by western blot analysis. Examination of Bcl-2 regulation in PG-treated cells revealed that Bcl-2 protein levels were reduced following treatment with 200-800 $\mu \mathrm{M}$ PG in both lung cancer cell types (Fig. 6A and B). Caspase-3 plays an essential role as an executioner in apoptosis (25). Whether 

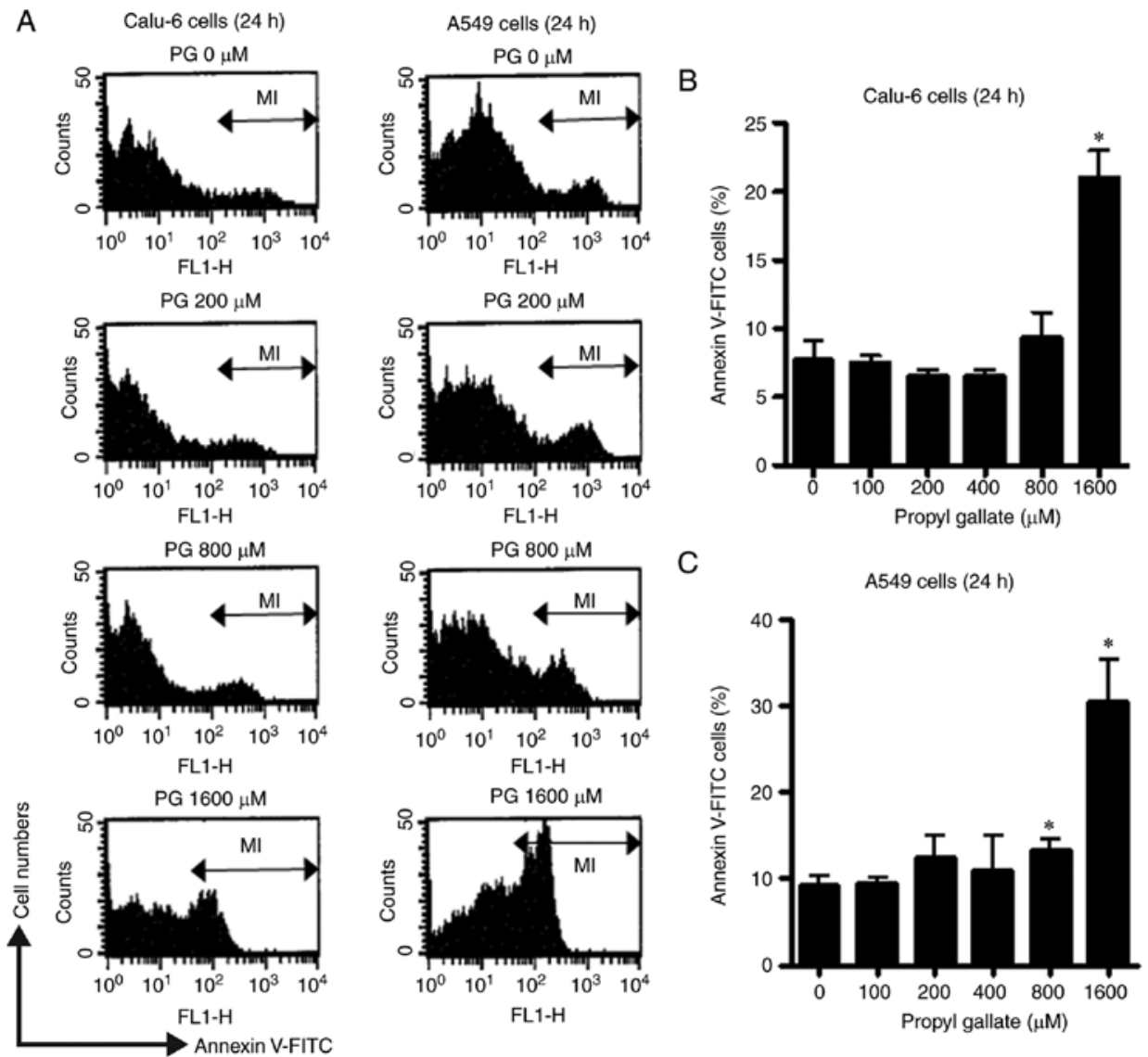

C

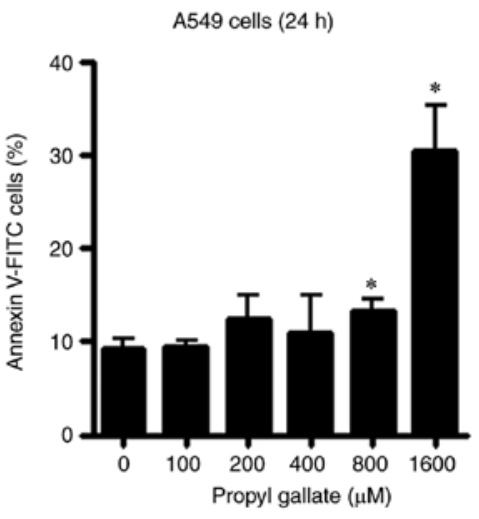

Figure 4. Effects of PG on cell death in lung cancer cells. Exponentially growing cells were incubated in the presence of the designated concentrations of PG for $24 \mathrm{~h}$. Annexin V-stained cells were assessed with FACStar flow cytometer. (A) Representative histograms for Annexin V-FITC staining in PG-treated Calu-6 and A549 cells. M1 indicates Annexin V-FITC-positive cells. (B and C) Graphs show the percentages of M1 regions in A in (B) Calu-6 and (C) A549 cells. ${ }^{*} \mathrm{P}<0.05$ compared with the PG-untreated control cells. PG, propyl gallate.
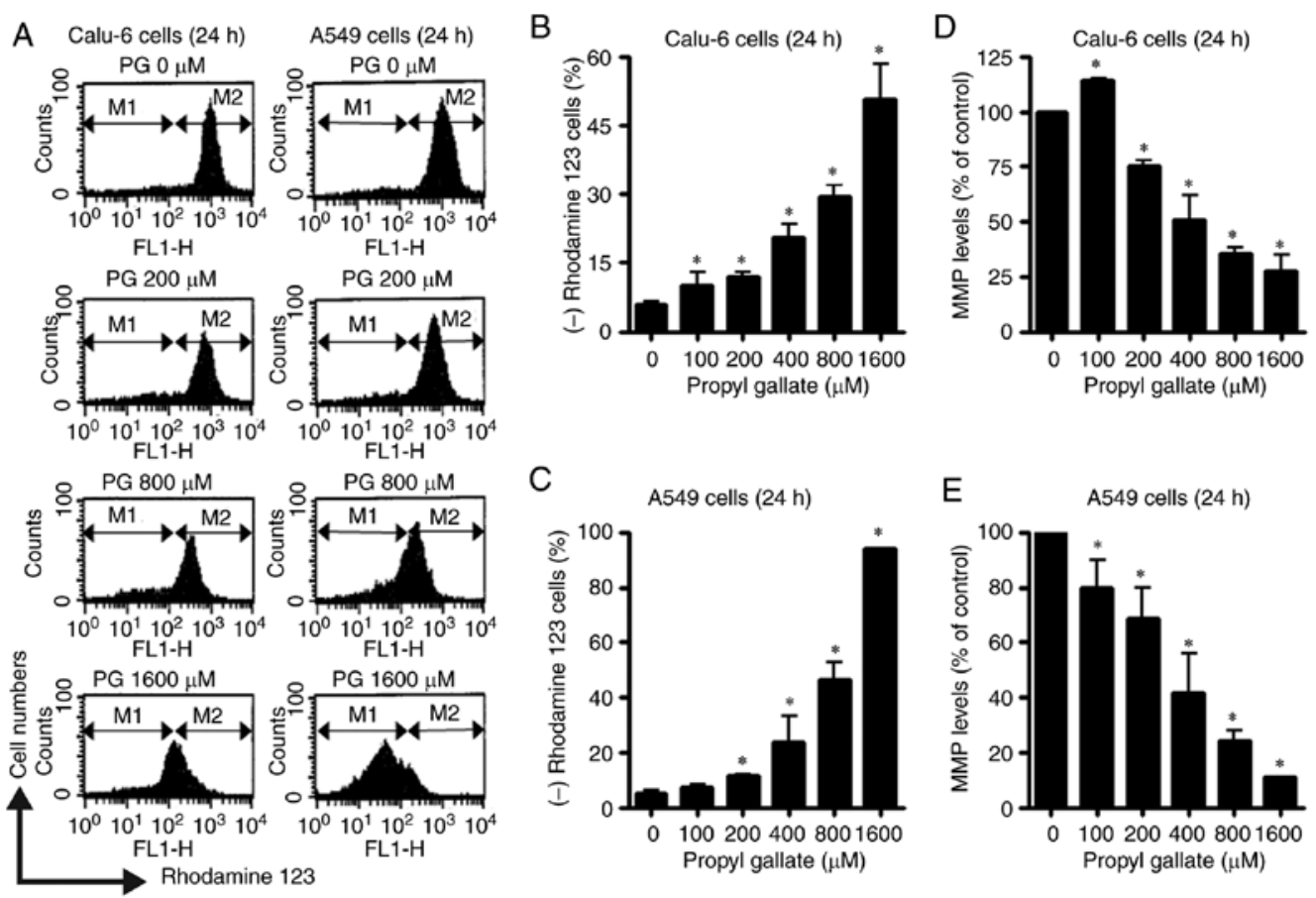

Figure 5. Effects of PG on mitochondrial membrane potential (MMP; $\Delta \Psi \mathrm{m}$ ) in lung cancer cells. Exponentially growing cells incubated in the presence of the designated concentrations of PG for $24 \mathrm{~h}$. MMP $(\Delta \Psi \mathrm{m})$ in lung cancer cells was measured using FACStar flow cytometer. (A) Representative histograms for Rhodamine 123 staining in PG-treated Calu-6 and A549 cells. M1 indicates Rhodamine 123-negative [MMP $\left(\Delta \Psi_{\mathrm{m}}\right)$ loss] cells. M2 indicates cells without MMP $(\Delta \Psi \mathrm{m})$ loss. (B and C) Graphs show the percentages of M1 regions in A in (B) Calu-6 and (C) A549 cells. (D and E) Graphs indicate the proportions of $\operatorname{MMP}(\Delta \Psi \mathrm{m})$ levels derived from M2 regions in A in (D) Calu-6 and (E) A549 cells. ${ }^{*} \mathrm{P}<0.05$ compared with the PG-untreated control cells. PG, propyl gallate. 
A

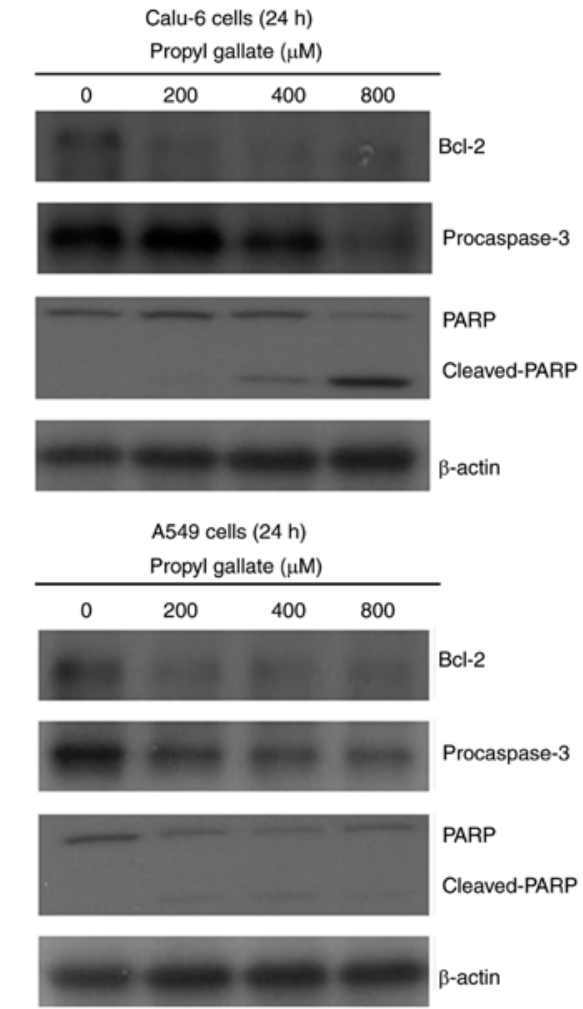

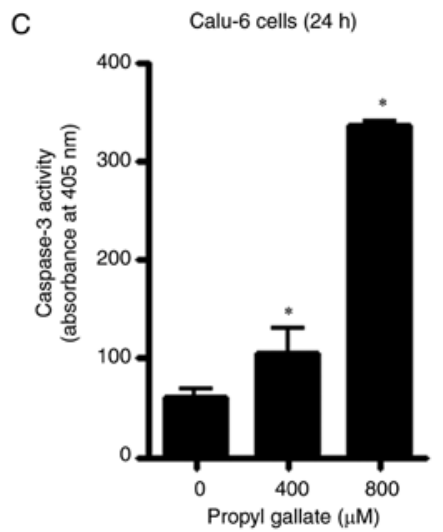

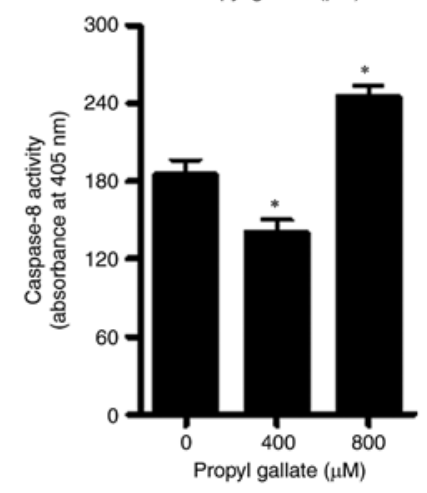

Figure 6. Effects of PG on apoptosis-related protein levels in lung cancer cells. Exponentially growing cells were incubated in the presence of the designated concentrations of PG $(0-800 \mu \mathrm{M})$ for $24 \mathrm{~h}$. Protein extracts were resolved via $8-15 \%$ SDS-PAGE gel, transferred to PVDF membranes, and immunoblotted with the designated antibodies. Western blot analysis shows the levels of Bcl-2, caspase-3, PARP and $\beta$-actin in the PG-treated (A) Calu-6 and (B) A549 cells (C) Graphs show the activities of caspase- 3 and caspase- 8 in Calu- 6 cells. ${ }^{*} \mathrm{P}<0.05$ compared with the PG-untreated control cells. PG, propyl gallate; PARP, poly(ADP-ribose) polymerase.

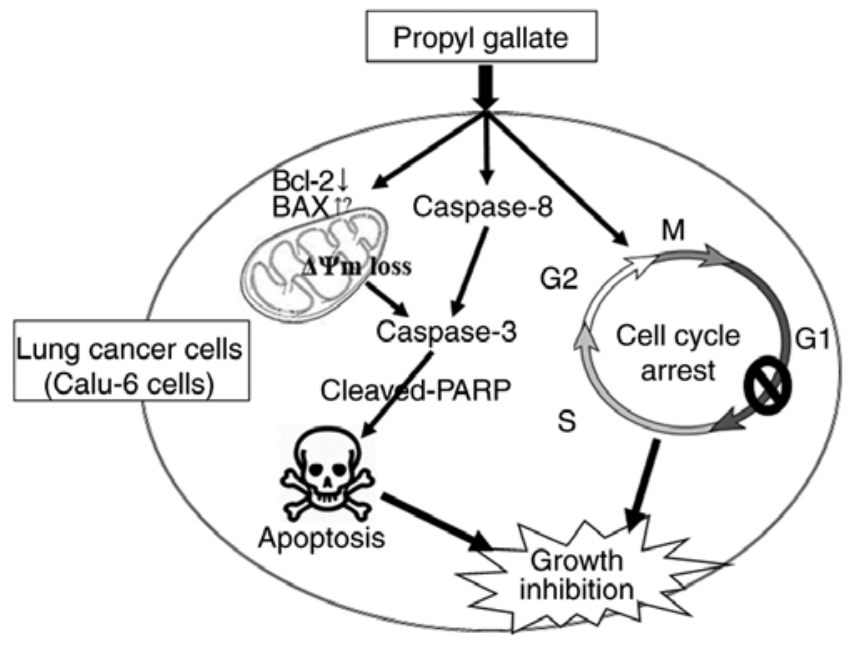

Figure 7. Schematic diagram of the anti-growth effects of PG on lung cancer cells, with a focus on SCLC Calu-6 cells. PG, propyl gallate; SCLC, small cell lung cancer; $\operatorname{MMP}\left(\Delta \Psi_{\mathrm{m}}\right)$, mitochondrial membrane potential.

PG activates caspase-3 in PG-treated lung cancer cells was also examined. Levels of procaspase-3 (32 kDa precursor) were visibly reduced following treatment with $400-800 \mu \mathrm{M}$ PG in the Calu-6 cells (Fig. 6A) and following treatment with 200-800 $\mu \mathrm{M}$ PG in the A549 cells (Fig. 6B). Cleavage of PARP provides one of the most recognizable markers of apoptosis (26). While the intact $116 \mathrm{kDa}$ moiety of PARP was reduced in the 400-800 $\mu \mathrm{M}$ PG-treated Calu6 cells, the cleaved form of PARP increased in these cells (Fig. 6A). PG at $200-800 \mu \mathrm{M}$ also reduced the intact form of PARP in the A549 cells (Fig. 6B). Furthermore, 400-800 $\mu \mathrm{M}$ PG treatment significantly increased caspase- 3 activities in the Calu- 6 cells (Fig. 6C). Caspase-8, which is correlated with the cell death receptor pathway (25), was also significantly activated by treatment with $800 \mu \mathrm{M}$ PG in Calu-6 cells (Fig. 6C). However, $400 \mu \mathrm{M}$ PG downregulated the activity of caspase-8, compared with basal activity of the control cells (Fig. 6C).

\section{Discussion}

Although propyl gallate (PG) is used to preserve and stabilize medicinal provisions included on the US Food and Drug Administration list (27), the latent toxicity of PG has been inspected to assess various in vivo or in vitro toxicological properties (2,28-30). In the present study, the anti-growth effects of PG were examined in Calu-6 and A549 lung cancer cell lines in relation to apoptosis as well as cell cycle arrest. Treatment with PG decreased the growth of both lung cancer cell types with an $\mathrm{IC}_{50}$ of approximately $800 \mu \mathrm{M}$ at $24 \mathrm{~h}$. Similarly, $800 \mu \mathrm{M}$ of PG was found to reduce the growth of HeLa cells by approximately $50 \%$ at $24 \mathrm{~h} \mathrm{(23).}$ However, $800 \mu \mathrm{M}$ PG was found to strongly reduce the growth of umbilical vein and pulmonary artery endothelial cells by more than $50 \%$ at $24 \mathrm{~h}$ and the susceptibility of pulmonary artery endothelial cells to PG was higher than 
that of umbilical vein endothelial cells (20). In addition, $400 \mu \mathrm{M}$ PG did not significantly inhibit the growth of primary human pulmonary fibroblasts at $24 \mathrm{~h}$ (31). Because PG can damage mitochondria which leads to ATP depletion $(9,20,23,32)$, the varying susceptibility to PG is perhaps owing to the different basal activities of mitochondria and antioxidant enzymes that each cell type has. Thus, the toxicity of PG should be carefully studied and interpreteted in vivo and in vitro depending on PG concentration, incubation time, and experimental target cells.

In the present study, PG induced the apoptosis of Calu- 6 and A549 cells, as demonstrated by the proportions of sub-G1 and Annexin V-stained cells. In addition, PG treatment clearly decreased the Bcl-2 levels, along with an increase in the cleavage form of PARP. DNA flow cytometry indicated that PG induced arrest at the G1 phase of the cell cycle in both lung cancer cell types at 24 and $72 \mathrm{~h}$. Similarly, PG was previously found to induce G1 phase arrest of the cell cycle along with an increase in p27, a cyclin-dependent kinase (CDK) inhibitor (CDKI), in HeLa cells (23). In the present study, treatment with $800 \mu \mathrm{M}$ PG inhibited the growth of lung cancer cells by approximately $50 \%$ but this dose of PG induced cell death by approximately $10 \%$ in view of the percentages of the sub-G1 cells and Annexin V-stained cells. Thus, the significant G1 phase arrest by PG is another conceivable underlying mechanism for the inhibition of cell growth. It is worthwhile to study whether PG affects the expression levels of cyclin, CDKs, and CDKIs to induce cell cycle arrest, especially at the G1 phase in lung cancer cells. Collectively, PG inhibits the growth of lung cancer cells via G1 phase arrest of the cell cycle as well as apoptosis.

Apoptosis is closely related to the failure of mitochondrial membrane potential [MMP $(\Delta \Psi \mathrm{m})]$ (33), and PG can cause a breakdown in MMP $(\Delta \Psi \mathrm{m})(9,20,23,32)$. In the present study, likewise, $\mathrm{PG}$ dose-dependently induced the loss of $\mathrm{MMP}(\Delta \Psi \mathrm{m})$ and reduced the MMP $(\Delta \Psi \mathrm{m})$ level in lung cancer cells. The degree of cells with MMP $(\Delta \Psi \mathrm{m})$ loss in the PG-treated Calu-6 (SCLC; small cell lung cancer) cells was lower than that in the PG-treated A549 (NSCLC; non-small cell lung cancer) cells. For example, $800 \mu \mathrm{M}$ of PG increased the percentage of cells with $\operatorname{MMP}\left(\Delta \Psi_{\mathrm{m}}\right)$ loss in the Calu-6 and A549 cell lines by approximately 30 and $45 \%$, respectively. While the level of $\operatorname{MMP}\left(\Delta \Psi_{\mathrm{m}}\right)$ was approximately $30 \%$ in the $800 \mu \mathrm{M}$ PG-treated Calu- 6 cells, the MMP $\left(\Delta \Psi_{\mathrm{m}}\right)$ level in A549 cells was approximately $20 \%$. Interestingly, the degree of MMP $(\Delta \Psi \mathrm{m})$ loss in the PG-treated lung cells was higher than that of the Annexin V-stained cells. Furthermore, the proportions of Annexin V-stained cells in the PG-treated Calu- 6 cells were lower than those in the A549 cells. These results imply that PG initially influences the mitochondrial membrane, especially in adenocarcinoma A549 (NSCLC) cells, which precedes the next step in apoptosis.

Apoptosis involves the mitochondrial (intrinsic) and cell death receptor (extrinsic) pathways (15). Caspase-3 plays a critical role as an executioner of apoptosis. The levels of procaspase-3 (32 kDa precursor) were reduced in the PG-treated lung cancer cells, which suggests that activation of caspase-3 occurred in these cells. In fact, PG treatment upregulated the activity of caspase- 3 in Calu- 6 cells. In particular, the activation of caspase- 8 was observed in apoptosis of Calu- 6 cells induced by PG. However, $400 \mu \mathrm{M}$ PG that showed a slightly decreased amount of Annexin V-stained cells lessened caspase-8 activity, compared with the basal activity of the control cells. Further research is required to elucidate the exact mechanism that is involved. Caspase- 8 activation is linked with the cell death receptor pathway of apoptosis $(25,34)$. PG-induced apoptosis in lung cancer cells involved both extrinsic and intrinsic pathways.

In conclusion, PG treatment inhibited the growth of lung cancer cells, especially Calu-6 cells via caspase-dependent apoptosis as well as G1 phase arrest of the cell cycle (Fig. 7). The presented data provides valuable information for understanding the cytotoxicological effects of PG in lung cancer cells in view of apoptosis and cell cycle arrest. Since PG has been reported to exert prooxidant properties $(6,7)$, it is worth studying whether PG induces apoptosis of Calu-6 and A549 lung cancer cells through oxidative stress in the future.

\section{Acknowledgements}

Not applicable.

\section{Funding}

The present study was supported by a grant (2019R1I1A2A01041209) of the Basic Science Research Program through the National Research Foundation (NRF) funded by the Ministry of Education, Republic of Korea.

\section{Availability of data and materials}

Data collected during the present study are available from the corresponding author upon reasonable request.

\section{Authors' contributions}

WHP conceived and designed the study, performed the experiments, and wrote the manuscript. WHP agrees to be accountable for all aspects of the research in ensuring that the accuracy or integrity of any part of the work are appropriately investigated and resolved.

\section{Ethics approval and consent to participate}

Not applicable.

\section{Patient consent for publication}

Not applicable.

\section{Competing interests}

The authors declare that they have no competing interests.

\section{Authors' information}

Professor Woo Hyun Park: ORCID: 0000-0003-4341-5188.

\section{References}

1. Final report on the amended safety assessment of propyl gallate. Int J Toxicol 26 (Suppl 3): 89-118, 2007. 
2. Wu TW, Fung KP, Zeng LH, Wu J and Nakamura H: Propyl gallate as a hepatoprotector in vitro and in vivo. Biochem Pharmacol 48: 419-422, 1994.

3. Reddan JR, Giblin FJ, Sevilla M, Padgaonkar V, Dziedzic DC, Leverenz VR, Misra IC, Chang JS and Pena JT: Propyl gallate is a superoxide dismutase mimic and protects cultured lens epithelial cells from $\mathrm{H} 2 \mathrm{O} 2$ insult. Exp Eye Res 76: 49-59, 2003.

4. Chen $\mathrm{CH}$, Liu TZ, Chen $\mathrm{CH}$, Wong $\mathrm{CH}$, Chen $\mathrm{CH}, \mathrm{Lu} \mathrm{FJ}$ and Chen SC: The efficacy of protective effects of tannic acid, gallic acid, ellagic acid, and propyl gallate against hydrogen peroxide-induced oxidative stress and DNA damages in IMR-90 cells. Mol Nutr Food Res 51: 962-968, 2007.

5. Hirose M, Yada H, Hakoi K, Takahashi S and Ito N: Modification of carcinogenesis by alpha-tocopherol, t-butylhydroquinone, propyl gallate and butylated hydroxytoluene in a rat multi-organ carcinogenesis model. Carcinogenesis 14: 2359-2364, 1993.

6. Kobayashi H, Oikawa S, Hirakawa K and Kawanishi S Metal-mediated oxidative damage to cellular and isolated DNA by gallic acid, a metabolite of antioxidant propyl gallate. Mutat Res 558: 111-120, 2004

7. Kawanishi S, Oikawa S and Murata M: Evaluation for safety of antioxidant chemopreventive agents. Antioxid Redox Signal 7: 1728-1739, 2005

8. Nakagawa Y and Tayama S: Cytotoxicity of propyl gallate and related compounds in rat hepatocytes. Arch Toxicol 69: 204-208, 1995.

9. Ham J, Lim W, Park S, Bae H, You S and Song G: Synthetic phenolic antioxidant propyl gallate induces male infertility through disruption of calcium homeostasis and mitochondrial function. Environ Pollut 248: 845-856, 2019.

10. Han YH, Moon HJ, You BR and Park WH: Propyl gallate inhibits the growth of calf pulmonary arterial endothelial cells via glutathione depletion. Toxicol In Vitro 24: 1183-1189, 2010.

11. Boyd I and Beveridge EG: Relationship between the antibacterial activity towards escherichia coli NCTC 5933 and the physico-chemical properties of some esters of 3,4,5-trihydroxybenzoic acid (Gallic acid). Microbios 24: 173-184, 1979.

12. Martinez-Alonso D and Malumbres M: Mammalian cell cycle cyclins. Semin Cell Dev Biol 2020 (Epub ahead of print).

13. Dalton S: Linking the cell cycle to cell fate decisions. Trends Cell Biol 25: 592-600, 2015.

14. Huska JD, Lamb HM and Hardwick JM: Overview of BCL-2 family proteins and therapeutic potentials. Methods Mol Biol 1877: 1-21, 2019.

15. Chung C: Restoring the switch for cancer cell death: Targeting the apoptosis signaling pathway. Am J Health Syst Pharm 75: 945-952, 2018.

16. Liu X, Yue P, Zhou Z, Khuri FR and Sun SY: Death receptor regulation and celecoxib-induced apoptosis in human lung cancer cells. J Natl Cancer Inst 96: 1769-1780, 2004.

17. Wurstle ML, Laussmann MA and Rehm M: The central role of initiator caspase-9 in apoptosis signal transduction and the regulation of its activation and activity on the apoptosome. Exp Cell Res 318: 1213-1220, 2012.
18. Hu Z, Li M, Chen Z, Zhan C, Lin Z and Wang Q: Advances in clinical trials of targeted therapy and immunotherapy of lung cancer in 2018. Transl Lung Cancer Res 8: 1091-1106, 2019.

19. Carter BW, Lichtenberger JP III, Benveniste MK, de Groot PM, Wu CC, Erasmus JJ and Truong MT: Revisions to the TNM staging of lung cancer: Rationale, significance, and clinical application. Radiographics 38: 374-391, 2018.

20. Han YH, Moon HJ, You BR, Yang YM, Kim SZ, Kim SH and Park WH: Propyl gallate inhibits the growth of endothelial cells, especially calf pulmonary arterial endothelial cells via caspase-independent apoptosis. Int J Mol Med 25: 937-944, 2010.

21. Chen $\mathrm{CH}$, Lin WC, Kuo $\mathrm{CN}$ and Lu FJ: Role of redox signaling regulation in propyl gallate-induced apoptosis of human leukemia cells. Food Chem Toxicol 49: 494-501, 2011.

22. Wei PL, Huang CY and Chang YJ: Propyl gallate inhibits hepatocellular carcinoma cell growth through the induction of ROS and the activation of autophagy. PLoS One 14: e0210513, 2019.

23. Han YH and Park WH: Propyl gallate inhibits the growth of HeLa cells via regulating intracellular GSH level. Food Chem Toxicol 47: 2531-2538, 2009.

24. Han YH, Moon HJ, You BR and Park WH: The anti-apoptotic effects of caspase inhibitors on propyl gallate-treated HeLa cells in relation to reactive oxygen species and glutathione levels. Arch Toxicol 83: 825-833, 2009.

25. Budihardjo I, Oliver H,Lutter M,Luo X and Wang X: Biochemical pathways of caspase activation during apoptosis. Annu Rev Cell Dev Biol 15: 269-290, 1999.

26. Lazebnik YA, Kaufmann SH, Desnoyers S, Poirier GG and Earnshaw WC: Cleavage of poly(ADP-ribose) polymerase by a proteinase with properties like ICE. Nature 371: 346-347, 1994.

27. Daniel JW: Metabolic aspects of antioxidants and preservatives Xenobiotica 16: 1073-1078, 1986.

28. Dacre JC: Long-term toxicity study of n-propyl gallate in mice. Food Cosmet Toxicol 12: 125-129, 1974

29. Rosin MP and Stich HF: Enhancing and inhibiting effects of propyl gallate on carcinogen-induced mutagenesis. J Environ Pathol Toxicol 4: 159-167, 1980.

30. Abdo KM, Huff JE, Haseman JK and Alden CJ: No evidence of carcinogenicity of D-mannitol and propyl gallate in F344 rats or B6C3F1 mice. Food Chem Toxicol 24: 1091-1097, 1986.

31. Park WH: Effects of antioxidants and MAPK inhibitors on cell death and reactive oxygen species levels in $\mathrm{H} 2 \mathrm{O} 2$-treated human pulmonary fibroblasts. Oncol Lett 5: 1633-1638, 2013.

32. Nakagawa Y, Nakajima K, Tayama S and Moldeus P: Metabolism and cytotoxicity of propyl gallate in isolated rat hepatocytes: effects of a thiol reductant and an esterase inhibitor. Mol Pharmacol 47: 1021-1027, 1995.

33. Yang J, Liu X, Bhalla K, Kim CN, Ibrado AM, Cai J, Peng TI, Jones DP and Wang X: Prevention of apoptosis by Bcl-2: Release of cytochrome c from mitochondria blocked. Science 275: 1129-1132, 1997.

34. Ashkenazi A and Dixit VM: Death receptors: Signaling and modulation. Science 281: 1305-1308, 1998. 